\title{
Fulfilled-expectations Equilibria in Network Demand
}

\author{
ADRIAAN TEN KATE \\ Head of the Economics Directorate, Federal Competition Commission, Mexico \\ GUNNAR NIELS * \\ Director, Oxera, UK
}

\begin{abstract}
Static demand models for homogeneous network goods give rise to fulfilled-expectations equilibrium demand (FEED) curves, which, contrary to normal demand curves, may be upward sloping at certain intervals. We analyze some, as yet unexplored, properties of the FEED curves. We spell out the one-shot non-cooperative game, the Nash equilibria of which constitute the FEED curve. We show that, in a network environment, pricing below marginal cost may be required to reach critical mass, and competition could represent an obstacle to network development rather than being its driving force.
\end{abstract}

\section{Introduction}

The essential characteristic of network demand is that the incentives of consumers to subscribe to the network become stronger as the number of subscribers grows. That is what distinguishes the demand for network goods from normal demand. In much of the literature on network economics this phenomenon is expressed by the assumption that each of the potential consumers has a private willingness to pay for buying the network good that increases with the network size. Ranking the consumers according to their willingness to pay at a given network size, and distributing them with a density function over some type interval, delivers a demand curve that expresses demand as a function of price and expected network size. If demand at a certain price happens to coincide with the expected network size, expectations are said to be fulfilled. The set of equilibria obtained in this way forms the fulfilled-expectations equilibrium demand (FEED) curve, which expresses price as a function of network size. This FEED curve may be of the well-known inverse-U shaped type.

In the early literature on network externalities, demand was modeled under less restrictive assumptions. For example, Rohlfs (1974) and Dybvig and Spatt (1983) assume that the utility that individual users derive from joining the network depends on who the

\footnotetext{
* Contact author: Dr Gunnar Niels, Oxera, Park Central, 40/41 Park End Street, Oxford, OX1 1JD, Oxford, UK; +44 1865 253029. Email: gunnar.niels@oxera.com We are grateful to two referees for invaluable comments. The usual disclaimer applies.
} 
other users are, not just on their number. Only when all users are equally important to all other users, the special case arises in which utilities depend on the size only, not on the composition of the subscriber base. Rohlfs calls this the uniform calling model.

We are fully aware that the network economics literature has grown exponentially since the Rohlfs, and Dybvig and Spatt articles, covering a wide range of areas such as pricing, standard-setting and, more recently, two-sided networks. Overviews of this literature can be found in Economides (1996), Farrell and Klemperer (2004), Stango (2004) and Roson (2005). Nonetheless, we consider that some properties of the FEED curve have not yet been fully explored in the literature. Since Rohlfs, and Dybvig and Spatt, most authors on network economics have elaborated further on the uniform calling model by specifying the shape of the network externality and choosing the consumer density function. In Katz and Shapiro (1985), consumer utility is assumed to be strictly additive between the consumer type (willingness to pay at zero network size) and an unspecified externality function. Economides and Himmelberg (1995) assume a multiplicative relationship between network externality and the consumer type. All these authors assume a uniform density function at a certain interval for the consumer type.

The purpose of this article is fivefold. First, it is to formulate the above indicated static demand system in more general terms than is ordinarily done. Second, it is to discuss the basic features of the fulfilled-expectations equilibrium demand curve and the concept of critical mass. The third objective is to spell out the underlying non-cooperative static game among the consumers and to demonstrate that the points of the FEED curve are Nash equilibria of this game. Fourth, we discuss the dynamic forces at work in the static demand model and finally, we examine the way in which conditions on the supply side may interact with the proposed demand model.

The article is limited to static demand models for a single homogeneous network good. As such, it does not address problems related to the choice between several competing networks. ${ }^{1}$ Moreover, it largely ignores the distinction between durable and non-durable network goods, a distinction that is relevant in the analysis of most real-world networks. In fact, for many networks, there are once-and-for-all entrance fees, yearly membership fees and separate service charges, which interact in a way which can only properly be captured by multi-period demand models, not by the model presented here.

The main focus of the article is on the demand side of the market. This means that, throughout, price is treated as an exogenous variable, not as the result of the interaction between producers and consumers. Only in the last two sections (sections 5 and 6) do we address aspects of supply, such as pricing strategies, production costs and whether the market is monopolistic or competitive.

We have organized this article into six sections. After this introduction we first spell out the demand system in algebraic terms and discuss its main assumptions. We then define the concepts of fulfilled-expectations equilibrium and critical mass and discuss their basic features. Next, we describe the static game the Nash equilibria of which constitute the fulfilled-expectations equilibrium demand curve. In section 5 we discuss some dynamic aspects of the demand model. In section 6 we consider how the supply side interacts with the demand side, followed by concluding comments.

\footnotetext{
${ }^{1}$ There is an extensive literature about competing networks. See, for example, Grilo et al. (2001).
} 


\section{The demand model}

In this section we set out the demand model, first specifying the willingness-to-pay function and then indicating how that leads to a demand function that depends on price and expected network size. A simplified presentation of this demand model is given in Ten Kate and Niels (2003).

\subsection{Willingness to pay and consumer typification}

Consumers are assumed to have a willingness to pay (or reservation price) for the network good, which depends on their type $y$ and on the size $n$ they expect the network to take. At a price lower than, or equal to, their willingness to pay they buy; otherwise they do not. If they buy, they buy only one unit. We assume the willingness to pay $w(y, n)$ to be a continuous and differentiable function in both arguments with positive partial derivatives in $y$ and $n$ :

\section{(1) (a) $\partial w / \partial y>0$ and (b) $\partial w / \partial n>0$}

A willingness-to-pay function depending on consumer type and network size assumes that all consumers of the same type value the size of the network in the same way. This assumption can be relaxed by allowing for multidimensional consumer types. This would, however, complicate the presentation without adding much further insight. The assumption that the partial derivative to $y$ is positive implies that the consumer typification is chosen such that the higher the type of the consumer, the higher their willingness to pay. It also implies that this holds for any network size; in other words, consumer ranking according to type is independent of network size. That the partial derivative to $n$ is positive reflects the fact that the willingness to pay increases along with the expected network size.

For simplicity, and without loss of generality, we write the willingness-to-pay function in the following form:

(2) $w(y, n)=y+u(y, n)$

with $u(y, 0)=0, \partial u / \partial y>-1$ and $\partial u / \partial n>0$. The second term $u(y, n)$ is called the externality function. Form (2) is obtained by transforming the original consumer type into a new type $y^{\prime}=w(y, 0)$. After the transformation consumers are typified by their reservation price at zero network size. ${ }^{2}$

It should be noted that this specification of the network externality is of a more general nature than the additive relations used by Katz and Shapiro (1985) and Cabral (1990) in which the externality function does not depend on the consumer type: that is $u(y, n)=u(n)$. It is also more general than the multiplicative relationship used by Economides and Himmelberg (1995) in which the externality is proportional to the consumer type: $u(y, n)=$ $y f(n)$.

Potential consumers are distributed over a type interval $\left(y_{\min }, y_{\max }\right)$ with a positive density function $f(y)$. The cumulated density $F(y)$ is decreasing in $y$ and $d F / d y=-f$. That is, $F(y)$ is cumulated from $y_{\max }$ downwards. The size of the consumer universe is $F_{0}=F\left(y_{\min }\right)$. In the transformed typification, $y_{\max }$ is the highest price at which the most interested

\footnotetext{
${ }^{2}$ Notice that this transformation does not work when consumers are not willing to pay anything for joining the network at size zero, regardless of their type. In this case consumers cannot be typified by their willingness to pay at zero network size, and one has to work with the original typification. The case would violate condition (1a) at $n=0$, however.
} 
consumers expecting zero network size buy. Likewise, $y_{\min }$ is the lowest price at which even the least interested consumers buy.

We allow for negative values of $y_{\min }$, not because we consider that some consumers might require compensation for joining the network rather than pay for it, but because the allowance of negative types introduces the possibility of distinguishing between different types of consumer who are not interested in joining at any price at zero network size but who would be interested at some positive size. Such consumers are now differentiated according to the network size at which they begin to be interested. (See Figure 1 in which consumers of type $y_{1}$ have a reservation price that turns positive at size $n_{1}$.)

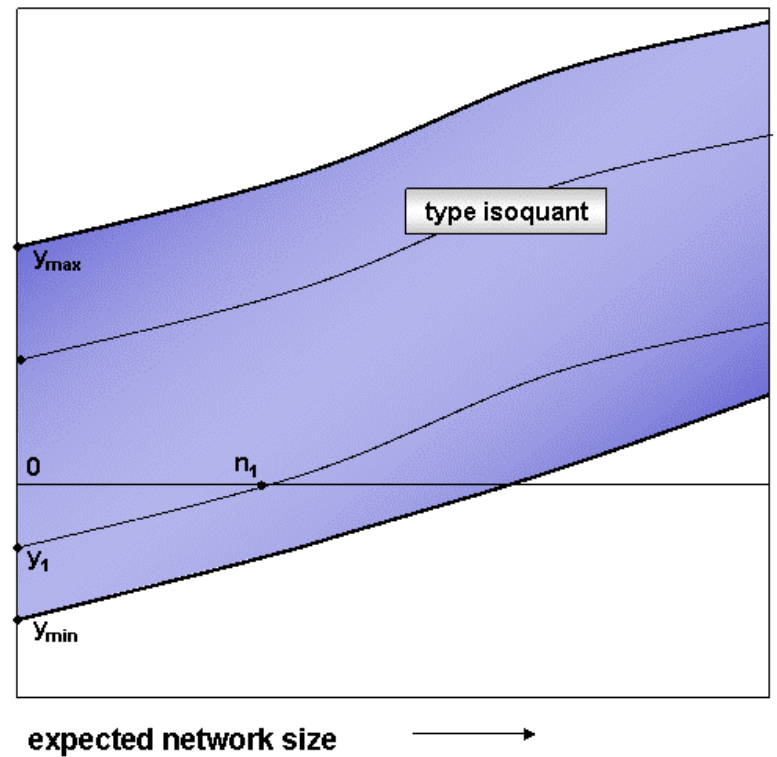

\section{Figure 1: Willingness to pay}

The figure shows how the willingness-to-pay range varies with expected network size. The most interested consumers follow the $y_{\max }$-isoquant; the least interested the $y_{\min }{ }^{-}$ isoquant. All other consumers have their willingness to pay somewhere within the shaded band. In principle $y_{\max }$ may also be negative. In this case not a single consumer expecting zero network size is willing to pay any price for entering, and a positive demand for the network good can only arise if at least some of the consumers expect others also to join.

To our knowledge, no other authors on the subject have allowed for negative reservation prices and, indeed, the economic sense of such prices is debatable. After all, as long as money is scarce, any compensation, however small, should be sufficient to convince consumers to accept something for free. As a counter-argument, there are many instances of network goods that seem to require heavy promotion campaigns (and sometimes even free rewards) in order to convince consumers to take up the offer at the introductory stages. Another reason why consumers of very different types may not be willing to enter a network of size zero, even when joining is free, is that network effects are often indirect and require the availability of complementary services which are only developed when the network has already been put into place. We avoid this controversy by 
interpreting the negative price range as virtual, not real. It becomes clear below that allowing for negative reservation prices simplifies the presentation of the demand system considerably.

\subsection{Demand and consumer surplus}

Demand for the network good is defined by the number of buyers. It depends on price and on the size consumers expect the network to take. We assume that all consumers expect the same network size, despite this being an unrealistic assumption. Since the final goal is to arrive at a fulfilled-expectations equilibrium, in which the obtained network size coincides with consumer expectations, there is no room for expectations to differ among consumers in such an equilibrium. Thus, at the end of the day the assumption is not restrictive. ${ }^{3}$

If all consumers expect a network size $n$, demand at price $p$ is obtained by pooling all consumers with a willingness to pay $w(y, n) \geq p$. These are the consumers with type $y \geq y_{0}$ where $y_{0}$ solves the equation $w(y, n)=p$. Demand is:

$$
D(p, n)=F\left(y_{0}(p, n)\right)
$$

Equation (3) determines demand in the shaded band of Figure 1. For points above the band, demand is zero; for points below the band, demand equals the consumer universe $\mathrm{F}_{0}$. From total differentiation of $\mathrm{w}(\mathrm{y}, \mathrm{n})=\mathrm{p}$, it follows that $\partial \mathrm{D} / \partial \mathrm{p}=-\mathrm{f}\left(\mathrm{y}_{0}\right) /(\partial \mathrm{w} / \partial \mathrm{y})<0$ and that $\partial \mathrm{D} / \partial \mathrm{n}=\mathrm{f}\left(\mathrm{y}_{0}\right)(\partial \mathrm{w} / \partial \mathrm{n}) /(\partial \mathrm{w} / \partial \mathrm{y})>0$. Hence, demand decreases with price and increases with expected network size. We call demand at $n=0$ baseline demand: $D_{b}(P)=D(p, 0)=F(p)$. Notice that baseline demand at price zero $D_{b}(0)=F(0)$ is smaller than the consumer universe when $\mathrm{y}_{\min }<0$. Inverting the demand function $\mathrm{D}(\mathrm{p}, \mathrm{n})$ in its first argument leads to an inverse demand function $\mathrm{D}^{-1}(\mathrm{~d}, \mathrm{n})$ which maps demand $\mathrm{d}$ to a price $\mathrm{p}$ with the mapping depending on $n$. Inverse baseline demand is $D_{b}{ }^{-1}(d)$.

The main characteristics of this demand system are illustrated in Figure 2. The horizontal axis of the right-hand part represents the network size $n$, and the vertical axis the price $p$, which, under specification (2), is commensurable with the consumer type $y$. To obtain demand at price $p$ and size $n$, one must start from point $(p, n)$ in the figure, then slide downwards along the type isoquant $p=y_{0}+u\left(y_{0}, n\right)$ to arrive at the vertical axis at point $y_{0}$, the type of the marginal consumer. To the left of the vertical axis, one finds the consumer density function, and the resulting demand is represented by the shaded area. ${ }^{4}$

In Figure 2 we chose $p>y_{\max }$, for illustrative purposes. At that price no consumer is willing to enter at the baseline, but expecting a network size $n$, all shaded-area consumers do enter.

This general specification of the demand function gives rise to a consumer surplus:

$$
Z(p, n)=\int_{p}^{\infty} D\left(p^{\prime}, n\right) d p^{\prime}
$$

Along with demand, consumer surplus also decreases with price and increases with network size. That is, $\partial Z / \partial p<0$ and $\partial Z / \partial n>0$.

\footnotetext{
${ }^{3}$ As explained in section 3 below, in the game-theoretical interpretation of the model the fulfillment of expectations is embodied in the concept of Nash equilibrium.

${ }^{4}$ It should be noted that an area on the left-hand side of the figure has the same dimension as the abscissa on the right-hand side - that is, the dimension of network size or demand.
} 


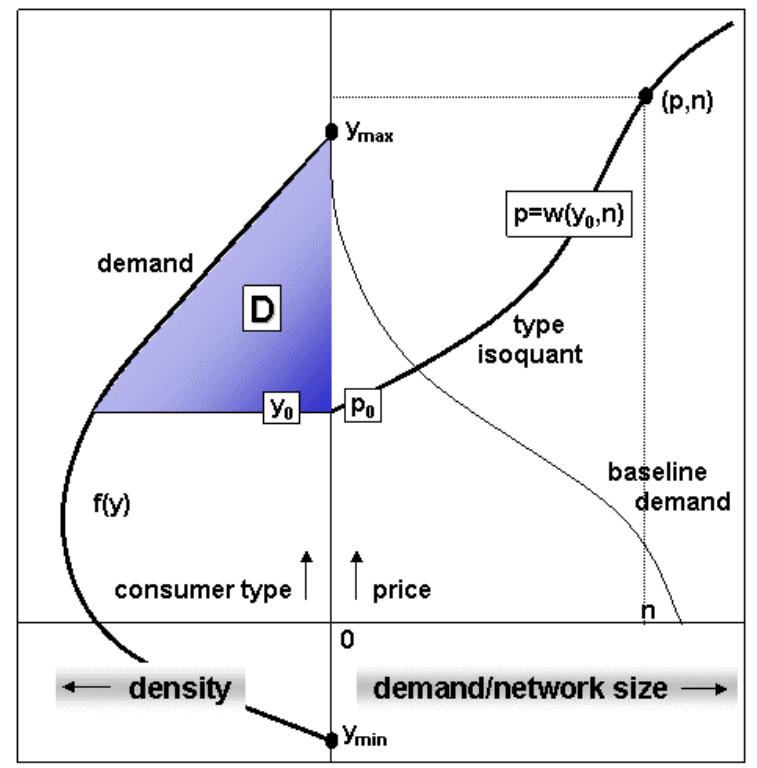

Figure 2: The demand system

\section{$3 \quad$ Fulfilled-expectations equilibria and critical mass}

\subsection{Fulfilled-expectations equilibrium}

A fulfilled-expectations equilibrium reflects the following situation: (i) all consumers expect a network size $n$; (ii) faced with a price $p$ they decide to buy or not to buy; (iii) aggregating the consumers who buy leads to a level of demand which happens to coincide with the expected network size. That is, expectations are fulfilled when

(5) $D(p, n)=n$

It is easy to see that, outside the shaded area of Figure 1, equation (4) can only be, and is indeed, satisfied for points at the price axis above $y_{\max }$ and for points at full network size $F_{0}$ under the shaded band. It is also clear that, whenever the willingness-to-pay and density functions are continuous, there is always one, and no more than one, $p$ satisfying (5) for every $n$ in $\left(0, F_{0}\right)$, and that the set of equilibrium points constitute a continuous and differentiable function: the fulfilled-expectations equilibrium demand (FEED) curve (see Figure 3).

Figure 3 shows a fairly general form of the FEED curve. However, depending on where the zero price line is located, part of the curve may be virtual. If the zero price line is at $\mathrm{A}$, the whole curve is in the positive price range. If, on the other hand, the zero price line is at $\mathrm{B}$, part of the curve is virtual (that is, in the negative price range). In the latter case the FEED curve consists of the positive part of the price axis; it is then interrupted to emerge again at network size $n$ and continues at positive price levels until reaching full network size. 


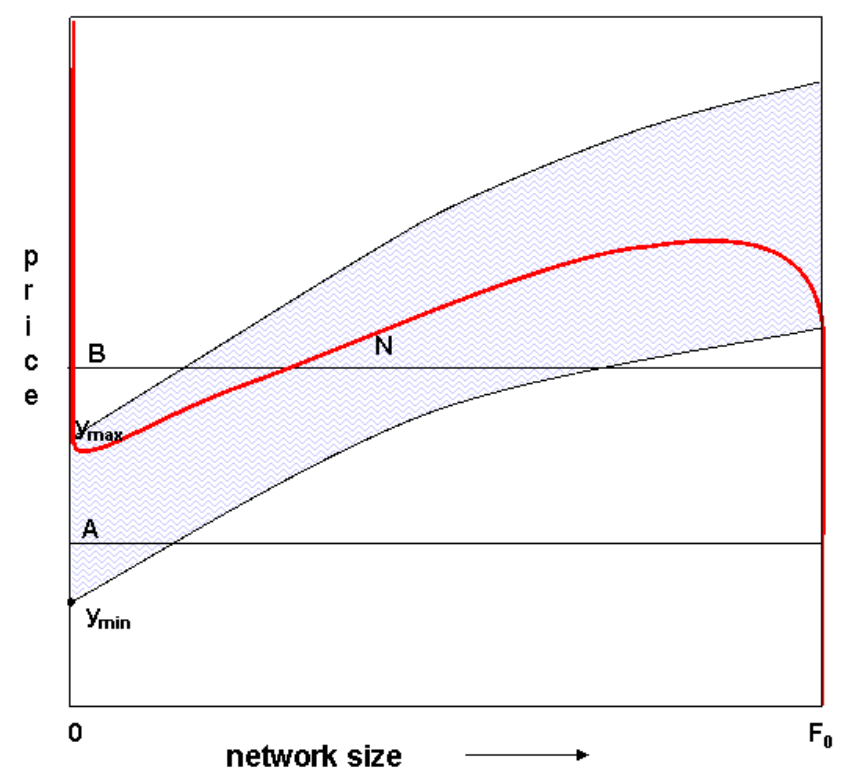

\section{Figure 3: FEED curve}

The FEED curve can be expressed as the inverse of the demand function:

(6) $p^{f e}(n)=D^{-1}(n, n)$

where the function $D^{-1}(d, n)$ is the inverse of $D(p, n)$ in its first argument. Figure 4 shows how the fulfilled-expectations equilibrium curve can be obtained graphically.

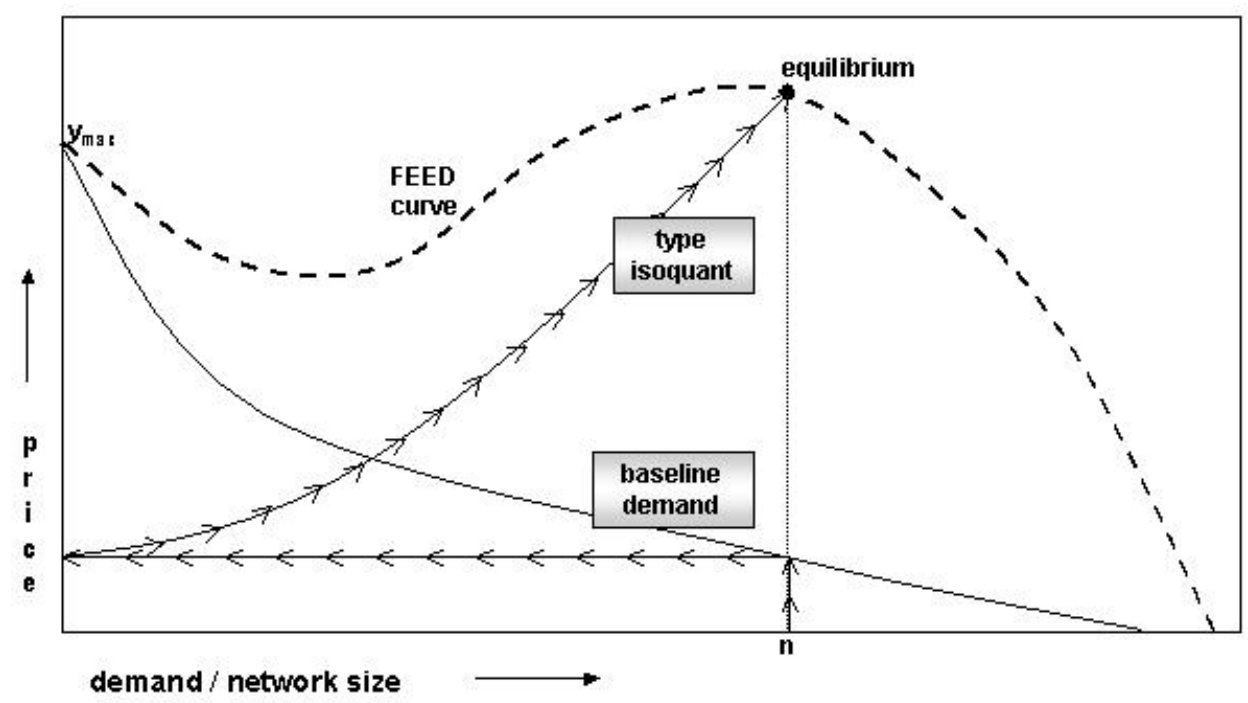

\section{Figure 4: Fulfilled-expectations equilibrium}

To find the equilibrium price $p$ corresponding to network size $n$, start off from the abscissa at network size $n$; then move vertically upwards (or possibly downwards if 
$\left.y_{\min }<0\right)$ to intersect with the inverse baseline-demand curve. Next, move horizontally to the left to intersect with the vertical axis; third, climb the corresponding type isoquant to the right until arriving again at network size $n$. That is the level of the corresponding equilibrium price $p^{f e}(n)$.

\subsection{Slope of the FEED curve}

Contrary to normal demand, FEED curves are not necessarily downwards-sloping everywhere. Totally differentiating the equilibrium condition $D(p, n)=n$, it is readily verified that the first derivative of the FEED curve is:

$$
\frac{d p^{f e}}{d n}=\frac{\left(1-\frac{\partial D}{\partial n}\right)}{\frac{\partial D}{\partial p}}=\frac{\partial w}{\partial n}-\frac{\frac{\partial w}{\partial y}}{f}
$$

The first term of the right-hand side of equation (7) represents the strength of the network externality. The second term is the inverse of the applicable consumer density $f$ multiplied by a scaling factor $\partial w / \partial y .^{5}$ Thus, where the network externality is stronger than the rescaled consumer density, the FEED curve is upward-sloping.

\subsection{Possible shapes of the FEED curve}

Different shapes of the FEED curve are shown in Figure 5. In Figure 5a the network externality is not sufficiently strong to bring about a positive slope at any network size. The FEED curve is similar to a normal demand curve, albeit somewhat less downwardsloping than it would otherwise have been. This curve might arise through the "bandwagon" effects discussed by Leibenstein (1950), which tend to make demand more elastic. Figure $5 \mathrm{~b}$ presents perhaps the most common form of the FEED curve in which it begins by sloping downwards, turns into an increasing function after passing through a minimum, reaches a maximum to become downward-sloping again, and finally arrives at full network size. If network externalities remain strong at full network size, and the density function drops discontinuously to zero at $y_{\min }$, the FEED curve can be as depicted in Figure 5c, where it arrives with a positive slope at full network size. Figure 5d shows a FEED curve as the one proposed by Economides and Himmelberg (1995). The departure of the FEED curve with a positive slope from the price axis is unlikely to occur in any practical case because it can only happen if the density function is discontinuous at $y_{\max }$. If the density function continuously starts from zero at $y_{\max }$ (which we consider to be the normal situation), it follows from equation (7) that the FEED curve departs smoothly from the price axis - that is, without a kink. For the same reason, the FEED curve always joins smoothly with the vertical full-network-size line unless the density function is discontinuous at $y_{\min }$.

\footnotetext{
${ }^{5}$ In our transformed consumer typification (2), this scaling factor $\partial w / \partial y$ is equal to 1 at $n=0$. At positive network sizes it may be different from 1, but at any such network size the typification could be chosen such that the scaling factor would equal 1 again.
} 


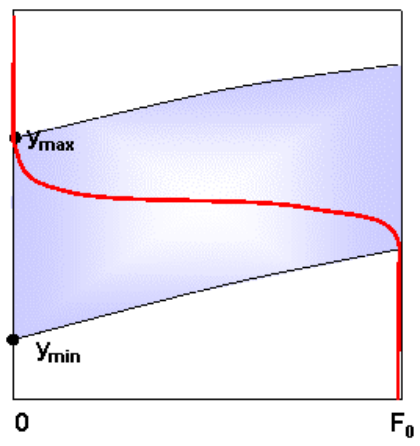

a. weak extemalities

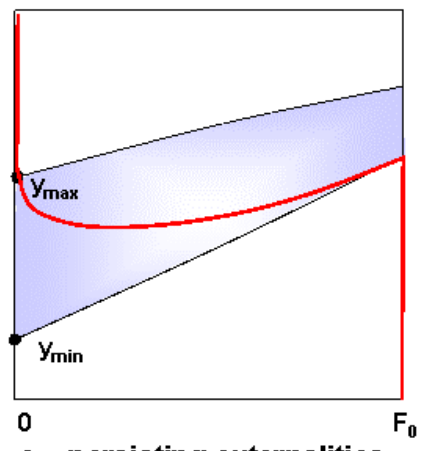

c. persisting externalities

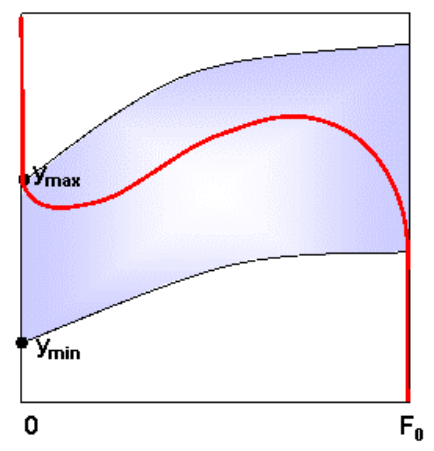

b. normal externalities

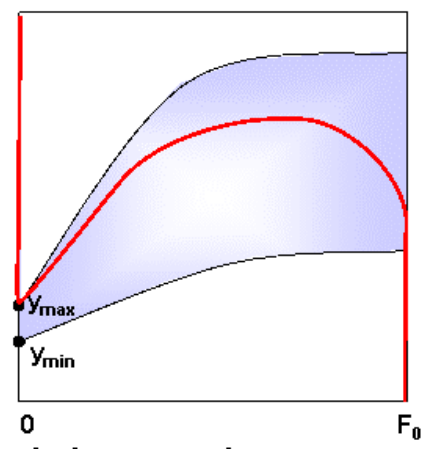

d. inverse-u shape

\section{Figure 5: Possible shapes of the FEED curve}

It should be kept in mind that all FEED curves in Figure 5 can be cut into a real and a virtual part depending on the height of the zero price line. On one hand, this can give rise to a missing part at small network sizes and, on the other, bring about a situation in which full network size is not attainable at a positive price. Moreover, it cannot be excluded that a FEED curve has not just one but several waves. This may be the case when the consumer density fluctuates or when the first derivative of the network externality function has several waves. However, we cannot provide an example of any real-world network showing such features under the assumptions of the uniform calling model.

\subsection{Critical mass}

As we explain below, equilibria at the upward-sloping part of the FEED curve are unstable. Small deviations tend to be self-reinforcing and may cause the network either to explode or to implode depending on the direction of the deviation. At such an equilibrium, a small push to the right is sufficient to make the network grow further on its own force and a push to the left to make it shrink. The network size at which this occurs is called the critical mass, and this depends on the price at which the network good is offered. In fact, the upward-sloping part of the FEED curve is the inverse of the critical mass curve.

The phenomenon of critical mass reflects the fact that, at the early stages of network development, consumers are reluctant to enter because of an insufficient number of subscribers. They must be pushed to enter - for example by introductory pricing. Once critical mass is reached, no further pushing is necessary. 


\section{$4 \quad$ A game-theoretical interpretation of the demand model}

Consider the non-cooperative one-stage game, the players of which are the potential consumers. Their possible moves are "buy" and "not buy", and the payoffs are their willingness to pay minus price if they buy and zero if they do not. Their willingness to pay is determined by their type and the network size, that is, the number of other players who choose to buy. Thus, for every price there is a well-defined game. The question is whether there are any Nash equilibria and, if so, which.

So far this game is similar to a normal demand model in which consumers buy if their willingness to pay is higher than the holding price and do not buy if it is lower. A normal demand model is not an interactive game, however, because in such a model the choices of the consumers are not interdependent. What makes the above-described game interactive is that the payoff to each individual consumer depends on the network size - that is, on the choices made by the other consumers.

Equilibria of the game corresponding to the normal demand model are of the typeseparating kind; in other words, given the price, there is a consumer type, say $y_{0}$, that separates buyers from non-buyers. Consumers with a higher type buy, consumers with a lower type do not; consumers of the type itself are indifferent. It is easy to show that, for a strategy profile to be a Nash equilibrium of the interactive demand model, it must also be of the type-separating kind.

To see this, one should first realize that, in any non-type-separating strategy profile, there is at least one pair of consumers of unequal types in which the higher type does not buy while the lower type does. If for the lower type buying is better than not buying, then it is also better for the higher type, and if, for the higher type, buying is worse than not buying, it is also worse for the lower type. Thus, in a non-type-separating strategy profile, at least one of the consumers plays suboptimally, which means that such a profile cannot be a Nash equilibrium.

A necessary condition for the type-separating strategy profile $\left\{y_{0}\right\}$ to be a Nash equilibrium to the game with price $p$ is that:

$$
w\left(y_{0}, F\left(y_{0}\right)\right)-p=0
$$

This is equivalent to the fulfilled-expectations equilibrium condition (5), but is now expressed in terms of the separating type instead of the network size. That is, a type $y_{0}$ satisfying (8) leads to network size $n=F\left(y_{0}\right)$ satisfying (5) and vice versa.

To prove that condition (8) is necessary, note that the left-hand side of equation (8) is exactly the payoff from buying for consumers with type $y_{0}$. The fact that it is zero means that consumers of type $y_{0}$ are indifferent between buying and not buying. It follows from the fact that $w(y, n)$ is a strictly increasing function in $y$ that the payoffs at network size $F\left(y_{0}\right)$ for consumer type $y$ are positive if $y>y_{0}$ and negative if $y<y_{0}$. Thus, all consumer choices are optimal given the choices of the other consumers. Likewise, if $y_{0}$ does not satisfy condition (8), all consumers between $y_{0}$ and the type that does satisfy (8) are playing suboptimally. Thus, a strategy profile $\left\{y_{0}\right\}$ not satisfying (8) cannot be a Nash equilibrium.

From this reasoning one would expect condition (8) to be not only necessary but also sufficient for a Nash equilibrium and this is indeed the case in the continuous consumer representation adopted in our model. Condition (8) simply guarantees that all players are playing optimally: those of type $y_{0}$ because they are indifferent (they can buy, not buy or 
adopt any mix), and those away from $y_{0}$ because their willingness to pay is at the correct side of price.

There is one thing, however, that is not properly accounted for in the approach adopted in our demand model in which consumers are treated as a continuum. It is that both buyers and non-buyers make their decision on the basis of one and the same network size. In reality, however, consumers are discrete entities and their willingness to pay depends not on the number of buyers, but on the number of other buyers, which means that non-buyers decided not to buy seeing the actual network size $n$, while buyers made their decision on the basis of a network size $n$-1. If $n$ is very large, as is supposed to be the case in the continuous consumer approach, the difference is very small. However, as soon as the consumers are considered as discrete entities, the difference is sufficiently large to upset the Nash condition for the marginal buyer or non-buyer at points where the FEED curve is positively sloped.

To see this, one should first realize that, however big the number of consumers in the universe, any individual player has a lower-type and a higher-type neighbour at a distance $\Delta y=1 / f$ which, however small, is positive. Let us now assume that there is a last buyer with type $y^{*}$, which means that all players with a higher type buy and all players with a lower type do not (and there is maybe one who mixes). The fact that the last buyer buys implies that that buyer's willingness to pay $w\left(y^{*}, F\left(y^{*}+\Delta y\right)\right)>p$. Note that this willingness to pay is determined by the number of other consumers $F\left(y^{*}+\Delta y\right)$ excluding that buyer. In that case, the buyer's lower-type neighbour at $y^{*}-\Delta y$ has a willingness to pay $w\left(y^{*}-\Delta y, F\left(y^{*}\right)\right)$, which in first-order Taylor expansion equals $w\left(y^{*}, F\left(y^{*}+\Delta y\right)\right)+(f \partial w / \delta n-\partial w / \delta y) \Delta y$. That is, the willingness to pay of the first non-buyer (mixer) is equal to the willingness to pay of the last buyer plus an extra term which equals the slope of the FEED curve times the density times $\Delta y$. Thus, where the slope is positive, the first non-buyer has a higher willingness to pay than the last buyer, which means that the first buyer would not be playing optimally.

Our conclusion is that, in what one may consider as the discrete consumer equivalent of the continuous consumer approach - that is, where discrete consumers are at a distance $1 / f$ from each other - there cannot be a last buyer, and thus no Nash equilibrium, in the range where the slope of the FEED curve is positive. To our knowledge, this lack of equilibrium behaviour at the upward-sloping part of the FEED curve has not been recognized in the literature on fulfilled-expectations equilibria. This is a technical peculiarity which reflects the instability of the fulfilled-expectations equilibria at the critical mass point.

It should be noticed that, in formulating this game, no mention was made of the expectations players had of the network size that will result from their decisions. The fulfilled-expectations character of the solution is implicit in the nature of the Nash equilibrium, which always implies a match between actions and beliefs; that is, in equilibrium, beliefs necessarily turn out to be correct. ${ }^{6}$

Contrary to the solutions of the demand model without externalities, the Nash equilibria of our game do not maximize consumer surplus at the given price. From a consumer surplus perspective, it would be preferable that some infra-marginal consumers buy at a loss in order to expand the network and so enhance the payoffs to the supramarginal consumers by more than their own losses. That is, there is incompatibility between collective and private incentives. Hence, maximum consumer surplus is not

\footnotetext{
${ }^{6}$ For such an interpretation of the Nash equilibrium, see Varian (1992, p. 265).
} 
reached under decentralized decision-making; to attain this, some form of cooperation between consumers would be necessary, or a subsidy to consumers from the firm(s) or an external party.

\section{Dynamics of the demand model}

To gain a proper understanding of the dynamic features of our demand system, consider the FEED curve in Figure 6. A point $(p, n)$ in price-network-size space represents a situation in which the network good is offered at price $p$, and $n$ is not the expected but the actual network size; that is, all consumers of a type higher than $y_{0}$ (chosen such that $\left.F\left(y_{0}\right)=n\right)$ buy and the others do not. The willingness to pay of the marginal consumer $w\left(y_{0}\right.$, $\left.F\left(y_{0}\right)\right)$ is then lower than $p$ above the curve and higher below. Thus, at a point below the curve, the marginal non-buyer regrets his decision of not having entered and with that buyer there is a type interval of non-buyers who share this regret. If those non-buyers were given a second chance they would enter. In other words, at every point below the curve there is a force at work towards network expansion, and the further away from the FEED curve the stronger these forces are.

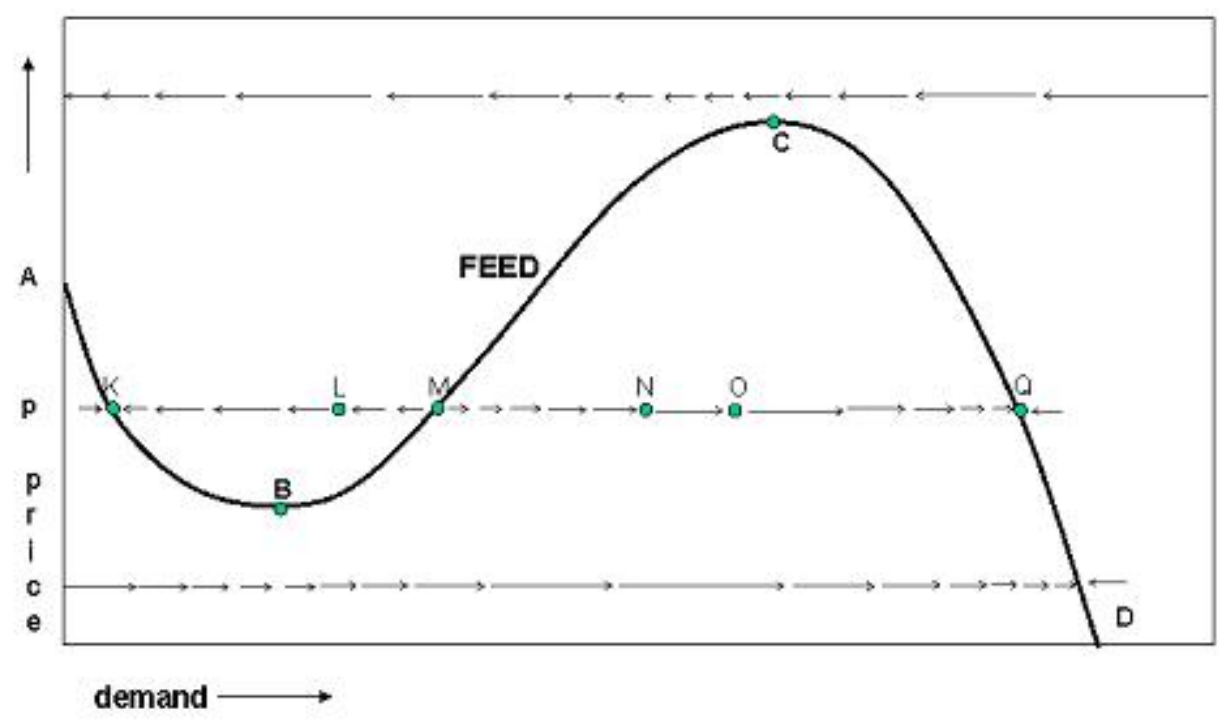

\section{Figure 6: Forces at work off-equilibrium}

Likewise, at points above the FEED curve the marginal buyer regrets his decision to enter, and with that buyer there is a type interval of buyers who also regret their decisions. Given a second chance, they would not buy any more and the network would shrink. Thus, above the curve there are forces at work towards network reduction; the further away from the curve, the stronger the forces.

In the figure these expansionary and contractionary forces are represented by arrows. For example, at point $\mathrm{N}$ to the right of the critical mass point $\mathrm{M}$, if buyers were given a second chance the network size would jump to $\mathrm{O}$. But at $\mathrm{O}$ there is a new group of nonbuyers who regret their decisions and who, given a third chance, would buy. This process 
continues until it becomes exhausted at the equilibrium Q. Beyond Q the tendencies are reversed. Likewise, at point $\mathrm{L}$ to the left of $\mathrm{M}$ there are buyers who regret their decision to buy and the forces are towards network reduction.

It follows that $\mathrm{Q}$ and $\mathrm{K}$ are stable equilibria. At these points arrows are directed towards the equilibrium. The critical mass point $M$ at the increasing part of the FEED curve, on the other hand, is not stable. Small disturbances cause the network size to float further away from the equilibrium value. A push to the right causes the network to explode all the way up to Q and a push to the left causes it to implode all the way down to K. This reflects our discussion above regarding the upward-sloping parts of the FEED curve not being Nash equilibria.

\section{$6 \quad$ Interaction with the supply side}

All characteristics discussed so far have nothing to do with the way in which the network good is supplied. Fulfilled-expectations equilibria, critical mass and expansionary and contractionary forces are properties of the demand system only. In this section we explore the implications of these properties for the pricing strategies that network providers may adopt under different conditions of supply. We consider two scenarios. First, we explore the case of a monopolistic network provider. Second, we analyse the scenario in which one and the same network good is offered by several competing suppliers. In the monopoly case we distinguish between durable and non-durable network goods, the former being goods bought once and serving for a lifetime (even if this lifetime is relatively short); the latter are goods that must be renewed at every period, such as memberships.

In what follows we deviate from the static approach of the demand model. Instead, we consider a situation in which demand does not instantaneously explode (or implode) to the corresponding equilibrium, but we assume that it takes time to convince consumers to join or leave the network. As in the previous section, we consider a time path, at each point of which consumers decide to join (stay with) or not to join (abandon) the network considering actual price and network size.

\subsection{Durable network good under monopoly}

Let us consider a monopolistic network provider facing a demand for its durable network good as depicted in Figure 6 above. Assuming its marginal costs to be constant and somewhere in between $\mathrm{B}$ and $\mathrm{C}$, the question is: starting from network size zero, how should the monopolist price its good over time (or over network size) in order to extract the maximum amount of profit from its sales?

If the monopolist is completely patient - that is, there is no time-discounting on its profits - the answer is simple. Its price path should be just below, but as close as possible to, the FEED curve (see Figure 7). The monopolist starts by setting its price at A and gradually lowers it to $\mathrm{R}$, thus skimming consumer surplus. It then "dives" with the price below its marginal cost, first moving to $\mathrm{B}$, where the network reaches critical mass, and continuing to S, where it can "breathe" again above marginal cost. Next, it moves up to C and finally skims consumer surplus down to $\mathrm{T}$, now at the mature-network-size part of the FEED curve. Its total profits amount to the sum of the shaded areas in Figure 7, counting the "under-water" (below-cost) part between $\mathrm{R}$ and $\mathrm{S}$ as negative profits. 


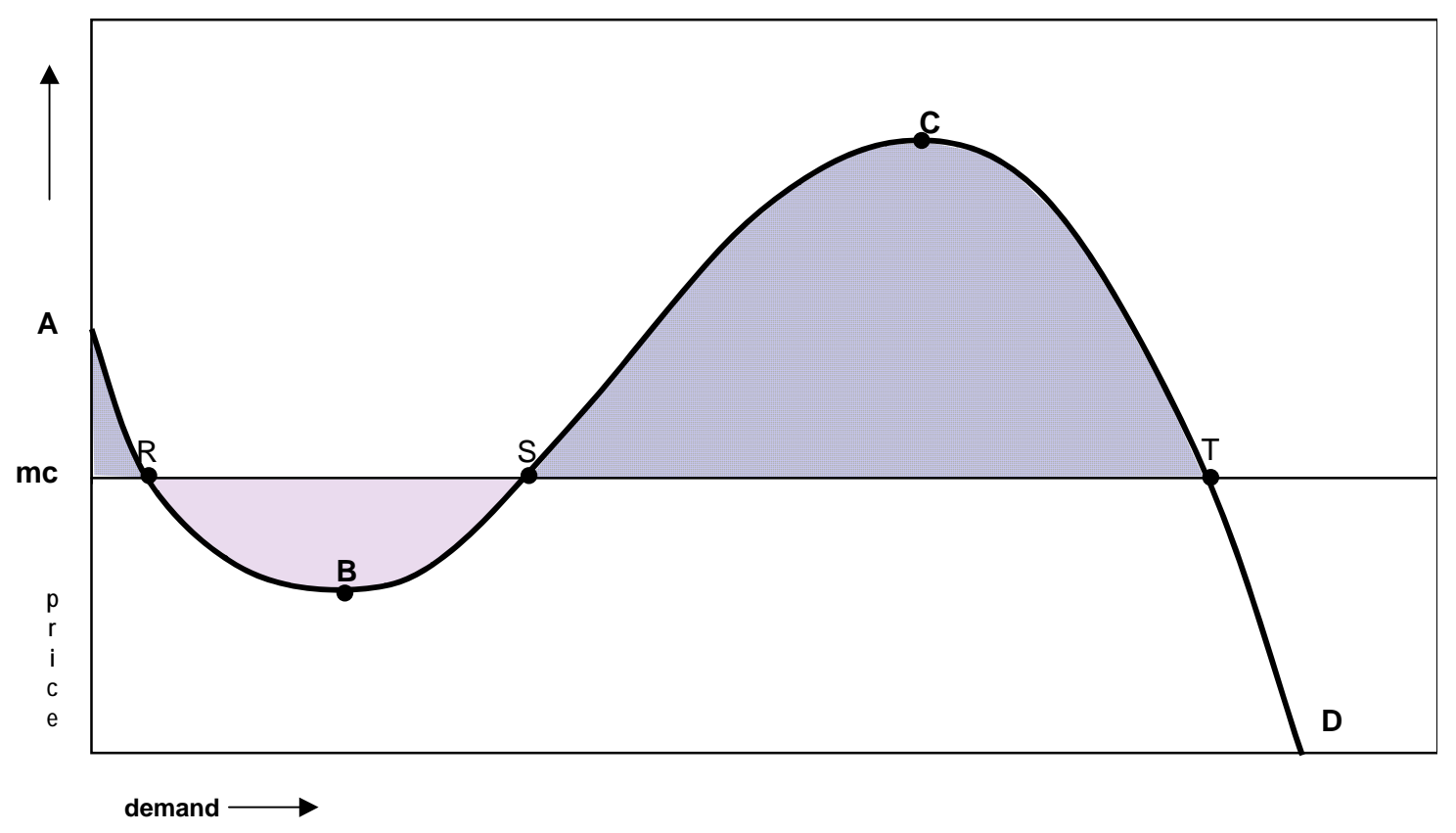

Figure 7: Pricing strategy for network development: completely patient monopolist with durable good

The above pricing pattern corresponds to first-degree price discrimination. The durable nature of the good allows the monopolist to wait at any point of the curve for the next marginal consumer to join, before lowering (or raising) its price further. As is well known, this first-degree price discrimination over time only works when consumers are shortsighted - that is, when they do not anticipate the monopolist's price movements. If, in contrast, consumers are forward-looking, they may postpone their decision to enter when they expect the price to fall, or bring it forward in time when they expect the price to rise. This would limit the monopolist's possibilities of perfect discrimination and its profits would be lower accordingly. Under our assumption that consumers base their decision to enter on the actual price and network size, they are indeed short-sighted.

It should be realized, however, that a pricing path of perfect discrimination may be a long walk. This is because close to the equilibrium curve forces are small; that is, the closer to the FEED curve, the slower the consumer reactions (as discussed in section 5 above). Thus, if the monopolist becomes somewhat impatient - time-discounting becomes positive - it will prefer a pricing path that is further below the FEED curve. The deeper it dives below the curve, the stronger the under-water currents driving it towards critical mass, as these forces are stronger when further away from the curve. Hence, there is a trade-off between the size of the initial losses and the time required to achieve mature network size and reap the benefits.

In principle, it is possible to calculate the optimal pricing path with techniques of variation calculus once the field of forces, the marginal cost curve, the discounting rate and consumer resistance (that is, how quickly they react to those forces) are given. In any event, price will have to be below marginal cost during some period in order to build up critical mass. Otherwise, demand remains trapped below the critical mass level and the network will never take off. 


\subsection{Non-durable network good under monopoly}

The picture is different for non-durable network goods. There, it becomes even more important to keep the time of diving below cost as short as possible, because during the dive, losses are incurred not only over new subscribers but also over subscribers who had joined the network previously (at least when the monopolist is not able to discriminate between new and existing subscribers). Hence, the device is: dive deep to make it short.

Another difference with the durable-goods case is that, once critical mass is reached, it no longer pays to follow the FEED curve all the way down to T. Instead, there is a monopoly point $\mathrm{E}$ at mature network sizes, where marginal revenue equals marginal cost (see Figure 8). The optimal pricing path for a non-discriminating monopolist leads to that point.

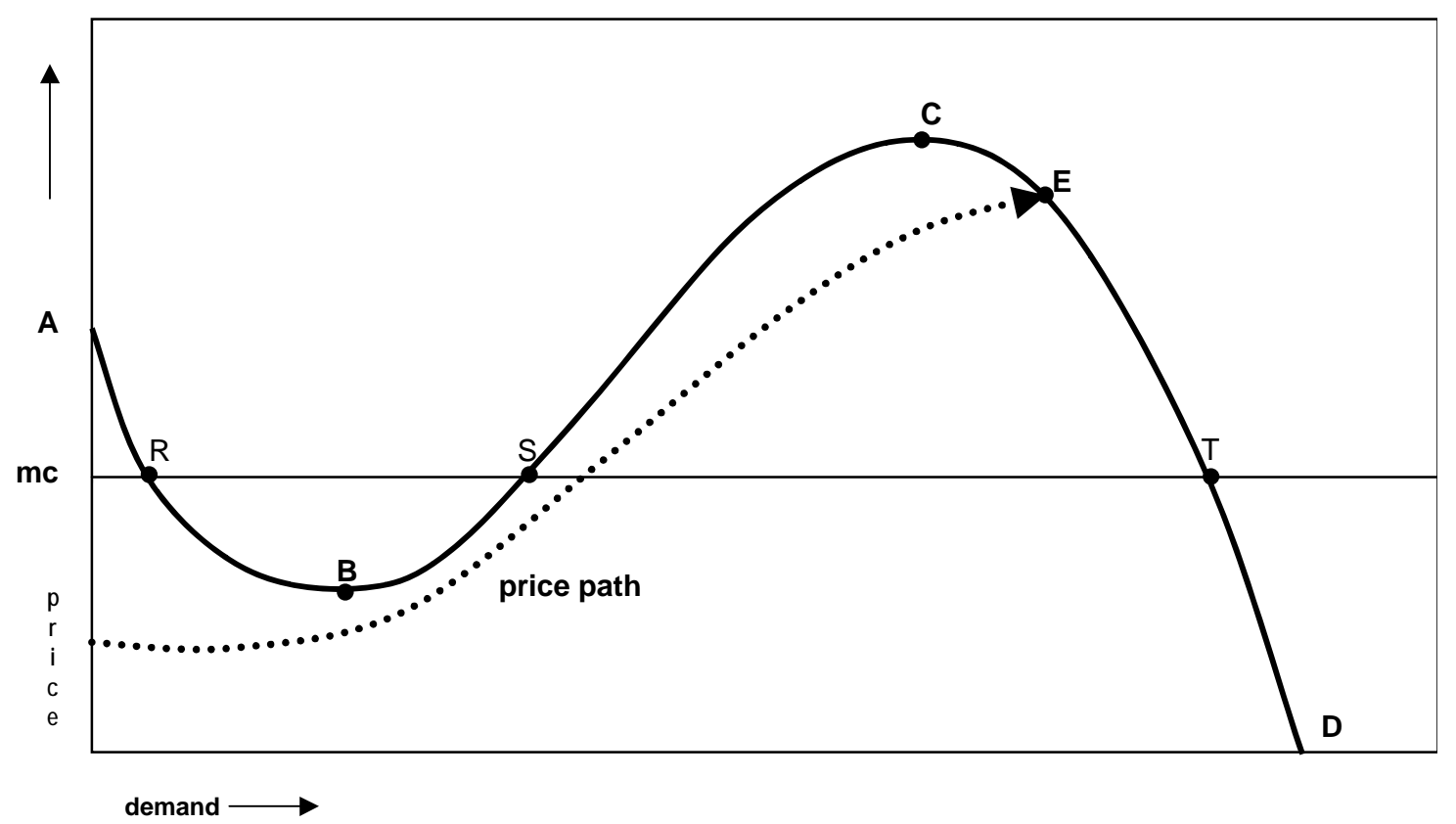

Figure 8: Pricing strategy for network development: monopolist with non-durable goods

Figure 8 illustrates what is likely to be an optimal price path for a monopolistic provider of a non-durable network good. The provider is not too interested in obtaining a positive profit from the part above marginal cost at the beginning of the FEED curve, but prefers to set an introductory price far below marginal cost in order to achieve critical mass as soon as possible. It will then swim upwards close to the FEED curve towards the "marginal-cost surface", take a breath, and fly on to the profit-maximizing point (here point E) where it will reap monopoly rents for as long as possible.

\subsection{A network good supplied by several competitors}

Let us now turn to a network industry with several competitors supplying a common network good. It should be noted in this case that any unit of the good sold by one of the competitors makes the network as a whole more attractive for consumers; hence, the other 
competitors also benefit. We assume that the alternative suppliers have similar costs which are above point $\mathrm{B}$ of Figure 6 . If all competitors starting from zero network size charge a price at, or above, their marginal cost, the network will never take off. This situation is basically the same as where the network is provided by a monopolist which sets price above marginal cost. Demand remains trapped on the left-hand side of the FEED curve (although perhaps at a somewhat lower price than under monopoly due to competition).

Thus, to start up the network someone must adopt a below-cost pricing strategy. The question then becomes: who is willing to do so? If one of the competitors begins to sell at a loss, critical mass will be reached, but as soon as that provider tries to raise its price its rivals will enter again and share the fruits of its sacrifices. Recoupment is therefore problematic. This is a typical free-rider problem in which no one takes the lead because the benefits of the costly initial move are not appropriable. Thus, under competition, the network is less likely to be developed than under monopoly.

From a competition point of view this is an extraordinary situation. Usually, competition is good for social welfare while monopoly is bad. Here the roles are inverted. A monopolist would have incentives to break away to critical mass by pricing below cost because future benefits are appropriable, but competitors would not because a large part of the benefits of a below-cost pricing effort by one of them would accrue to its competitors. Market level network externalities thus turn the conventional economic logic upside down.

\section{Concluding remarks}

In this article we have explored a number of properties of fulfilled-expectations equilibria in network markets that have thus far received little attention in the literature. We have focussed mainly on the demand side, explaining why equilibria on the upward-sloping parts of the FEED curve constitute the critical mass curve and are unstable equilibria. We then discussed some interactions with the supply side. A large body of literature on network economics has developed over the last decades, and various policy implications have been drawn from this literature, in particular for the purpose of competition law and regulatory policy. Some of these policy implications follow directly from our discussion of the interaction between network demand and the supply side. In particular, our exposition shows that, in several different circumstances, pricing below marginal cost may well be required for a network to reach critical mass. This means that standard competition tests for predatory pricing, which are often based on some variant of marginal cost, may be inappropriate for network markets. From our article it follows that, under the competitive supply of the network good, a free-rider problem may prevent the network from taking off in the first place. The policy implication is that competition authorities and regulators should be careful not to impose interconnection or interoperability requirements at too early a phase of network development because such requirements may erode the appropriability of the increase in network value by network developers.

\section{References}

Cabral, L. (1990) "On the Adoption of Innovations with Network Externalities," Mathematical Social Sciences, 19: 229-308. 
Dybvig, P.H. and C.S. Spatt (1983) "Adoption Externalities as Public Goods," Journal of Public Economics, 20: 231-47.

Economides, N. (1996) “The Economics of Networks," International Journal of Industrial Organization, 14: 673-99.

Economides, N. and C. Himmelberg (1995) "Critical Mass and Network Size with Application to the US Fax Market," Discussion Paper EC-95 - 11, Stern School of Business, New York.

Farrell, J. and P. Klemperer (2004) "Coordination and Lock-in: Competition with Switching Costs and Network Effects," preliminary draft chapter for Handbook of Industrial Organization, Vol. 3.

Grilo, I., O. Shy and J.F. Thisse (2001) "Price Competition when Consumer Behavior is Characterized by Conformity or Vanity," Journal of Public Economics, 80: 385-408.

Kate, A. ten and G. Niels (2003) "Below-cost Pricing in the Presence of Network Externalities," The Pros and Cons of Low Prices, Swedish Competition Authority, 97-127.

Katz, M. and C. Shapiro (1985) "Network Externalities, Competition and Compatibility," American Economic Review, 75: 424-40.

Leibenstein, H. (1950) "Bandwagon, Snob and Veblen Effects in the Theory of Consumers' Demand," Quarterly Journal of Economics, 54: 183-207.

Rohlfs, J. (1974) “A Theory of Interdependent Demand for Communications Service," Bell Journal of Economics, 5: 16-37.

Roson, R. (2005) "Two-sided Markets: A Tentative Survey," Review of Network Economics, 4: 142-160.

Stango, V. (2004) “The Economics Standards Wars," Review of Network Economics, 3: 119.

Varian, H. (1978) Microeconomic Analysis. Third Edition. Norton: New York. 